\title{
Electrocardiographic Abnormalities in Hypertension Models
}

Ana Gabriela Conceição-Vertamatti, ${ }^{\circledR}$ Filipy Borghi, ${ }^{\circledR}$ Larissa Yuri Ishizu, ${ }^{\circledR}$ Gustavo Trevisan Costa, ${ }^{\circledR}$ Luiz Alberto Ramos, ${ }^{\circledR}$ Miguel Arcanjo Areas, ${ }^{\circledR}$ Dora Maria Grassi-Kassisse

UNICAMP - Universidade Estadual de Campinas, Campinas, SP - Brazil

\section{Abstract}

Background: Hypertensive condition can lead to abnormalities in heart structure and electrical activity. The electrocardiogram (ECG) is a recording of the electrical activity of the heart and widely used to diagnose and detect heart problem.

Objective: We conducted a comparative ECG analysis between two hypertension models (L-NAME and SHR) and their controls (Wistar and Wistar-Kyoto) at six and $15^{\text {th }}$ week of age.

Methods: Blood pressure was measured at the end of the $15^{\text {th }}$ week, and electrocardiography was performed at six and 15 weeks of age in anaesthetized rats. Data normality was confirmed by Kolmogorov-Smirnov test followed by unpaired Student's t-test and the Mann-Whitney for parametric and non-parametric data, respectively. Results are expressed as mean \pm SD. The accepted level of significance was set at $\mathrm{p}<0.05$.

Results: L-NAME exhibited prolongation of JT and QT intervals and SHR showed a decrease in heart rate when compared to Wistar-Kyoto and L-NAME. Wistar-Kyoto exhibited short PR interval with increased QRS complex, and only QT prolongation at 15 weeks compared to Wistar.

Conclusions: All the hypertension models used in this study featured an increase in blood pressure. However, while SHR showed cardiac dysfunction, L-NAME exhibited changes in ventricular performance. These results may guide future studies on different types and models of hypertension. (Int J Cardiovasc Sci. 2020; 33(4):321-328)

Keywords: Rats; Hypertension; Blood Pressure; Electrocardiography/methods; NG-Nitroarginine Methil Éster/ adverse effects; Rats, Inbred (SHR).

\section{Introduction}

Prolonged exposure to stressors can lead to changes in the adaptive systems and consequently increased circulating levels of cortisol and adrenaline. ${ }^{1-3}$ This imbalance can result in several types of diseases, including cardiovascular diseases, which are the leading cause of death in the world. ${ }^{4}$ The development of hypertension may be associated with sympathetic overactivity, however the underlying mechanisms that surround the pathogenesis of hypertensive disease are complex and challenging, encouraging researchers to elucidate these mechanisms. ${ }^{5-7}$
Animal models are critical to advancements in medical research and provide valuable information regarding many aspects of the disease..$^{8-10}$ Classically, there are two well established models of sympathetic overactivity: the NG-monomethyl-L-arginine methyl ester (L-NAME)-induced hypertension and the spontaneously hypertensive rats (SHR). ${ }^{10}$

Hypertensive condition can lead to abnormalities in cardiac structure, and consequent dysfunction in cardiac electrical activity. ${ }^{11,12}$ The electrocardiogram (ECG) is a recording of the electrical activity of the heart and widely used to diagnose and detect heart problems. ${ }^{13}$ This test shows typical upward and downward

Mailing Address: Dora Maria Grassi-Kassisse

Rua Monteiro Lobato, 255. Postal Code: 13083-872, Campinas, SP - Brazil.

E-mail: doramgk@unicamp.br 
deflections (waves) that reflect the alternate contraction of the atria and the ventricles. ${ }^{14}$ The first wave, $\mathrm{P}$, is due to atrial contraction and its prolongation has been associated with hypertension caused by endothelial dysfunction and interatrial conduction delay. ${ }^{12,15}$ The $\mathrm{Q}, \mathrm{R}, \mathrm{S}$ complex indicates ventricular depolarization. ${ }^{12}$ The duration of the QRS interval and the amplitude of the waves separately are related to mortality in hypertension. ${ }^{16,17}$ The final wave, named $\mathrm{T}$, represents the repolarization of the ventricles and its correlation with the QRS complex (QT-interval). It is an important marker of ventricular activity and has been shown to have clinical utility. ${ }^{12,18}$ In the present study, we aimed to conduct a comparative ECG analysis between two hypertension models (L-NAME and SHR) and their controls (Wistar and Wistar-Kyoto).

\section{Methods}

Animals

Studies were conducted with adult, male, six and 15-week-old Wistar (HanUnib:WH), Wistar-Kyoto (NTacUnib:WKY) and SHR (SHR/NTacUnib) rats (Rattus norvegicus). All animals were provided by the Multidisciplinary Center for Biological Research (CEMIB - UNICAMP). The rats were housed in collective cages ( 3 rats per cage) at $22^{\circ} \mathrm{C}$ on a $12 \mathrm{~h}$ light-dark cycle (lights on at 06:30 a.m.) with ad libitum access to standard chow (Labina Purina ${ }^{\circledR}$ ) and filtered water. All animal housing, animal care and experimental procedures, and sample size were approved by the Ethics Committee on Animal Experimentation (CEUA) of the Institute of Biology of Unicamp in Campinas, Brazil (no. 2615-1), in accordance with the NIH guidelines. The animals were divided into four groups: control Wistar (WIS, $n=6$ ), induced hypertension (L-NAME, $\mathrm{n}=6$ ), control Wistar Kyoto (WKY, n = 6), and genetic hypertension (SHR, $n=6)$. For the L-N AME group, we inhibited nitric oxide synthesis by administration of L-NAME (Enzo Life Sciences International, Inc.5120 Butler Pike, Plymouth Meeting, PA 19462) $40 \mathrm{mg} / \mathrm{kg} /$ day, for 5 weeks in the drinking water, started at the $10^{\text {th }}$ week of life of WIS. ${ }^{19}$ Water was changed three times a week, with correction in dose/weight. The rats were anesthetized with tiletamine $29 \mathrm{mg} \mathrm{kg}^{-1}$ and zolazepam $29 \mathrm{mg} \mathrm{kg}^{-1}$, i.p. (Zoletil 50 ${ }^{\circledR}$ - Virbac Laboratories, Carros, France); and xylazine $12.88 \mathrm{mg} \mathrm{kg}^{-1}$, i.p. (Anasedan ${ }^{\circledR}$ - Sespo Ind. e Com. Ltda, Paulínia/SP, Brazil).

\section{Blood Pressure}

Blood pressure monitoring was performed at the end of the $15^{\text {th }}$ week under anaesthesia. Blood catheterization was performed by insertion of a cannula (PE 50) into the right carotid artery of anesthetized animals, attached to a straingauge pressure transducer that was connected to a MLS370 amplifier/7 blood pressure Module (ADInstruments Australia), and to the data acquisition system PowerLab $8 / 30$. For analysis of the results, we used the Software LabChart Pro (ADInstruments - Australia). ${ }^{20}$

\section{Electrocardiography}

Electrocardiography was performed in anesthetized rats in the supine position during spontaneous breathing. Recordings were performed at 6 and 15 weeks of age, using hypodermic needle electrodes, with computerized electrocardiography (MLS360/7 ECG Analysis Module, ADInstruments, Australia), for five minutes. ${ }^{21}$

\section{Statistical Methods}

Data are presented as mean \pm SD. Normality of data distribution was confirmed by Kolmogorov-Smirnov test and then we performed unpaired Student's t-test for parametric and the Mann-Whitney test for nonparametric data. All statistical analysis was performed with Graph Pad Prism version 7.00 for Windows (Graph Pad Software, San Diego, California, USA). The accepted level of significance was $\mathrm{p}<0.05$.

\section{Results}

\section{Blood pressure}

L-NAME and SHR 15-week-old rats exhibited increased systolic blood pressure, diastolic blood pressure, mean diastolic pressure and mean pressure when compared to their respective controls, WIS and WKY rats. There were no differences in systolic blood pressure, diastolic blood pressure, mean diastolic pressure and mean pressure between hypertensive rats (L-NAME vs. SHR) and control groups (WIS vs. WKY). Peak time was higher in SHR when compared with WKY but was not different when compared with L-NAME. No difference was observed in this parameter in control rats. There were no differences in pulse pressure, ejection and non-ejection time and cycle duration between the study groups (Table 1). 
Table 1 - Evaluation of blood pressure in hypertensive (L-NAME and SHR) and normotensive (WIS and WKY) rats at 15 weeks of age

\begin{tabular}{|c|c|c|c|c|}
\hline & WIS & L-NAME & WKY & SHR \\
\hline Systolic pressure & $118.8 \pm 16.53$ & $156.4 \pm 30.35^{*}$ & $119.5 \pm 11.64$ & $139.4 \pm 12.84^{*}$ \\
\hline Diastolic pressure & $96.28 \pm 20.05$ & $133.6 \pm 31.35^{*}$ & $95.85 \pm 16.58$ & $114.6 \pm 13.85^{*}$ \\
\hline Pulse pressure & $22.54 \pm 10.44$ & $22.83 \pm 4.91$ & $23.61 \pm 5.23$ & $24.86 \pm 5.56$ \\
\hline Mean pressure & $106.9 \pm 22.58$ & $145.2 \pm 30.28^{*}$ & $107.1 \pm 15.57$ & $127.1 \pm 12.88^{*}$ \\
\hline Ejection time (s) & $0.0608 \pm 0.0083$ & $0.0736 \pm 0.0385$ & $0.0616 \pm 0.0092$ & $0.0690 \pm 0.0220$ \\
\hline Non-ejection time (s) & $0.0777 \pm 0.0123$ & $0.0897 \pm 0.0196$ & $0.0811 \pm 0.0122$ & $0.0895 \pm 0.0268$ \\
\hline Cycle duration (s) & $0.1389 \pm 0.0187$ & $0.1496 \pm 0.0245$ & $0.1421 \pm 0.0208$ & $0.1555 \pm 0.0246$ \\
\hline Time to peak (s) & $0.0309 \pm 0.0115$ & $0.0399 \pm 0.0076$ & $0.0230 \pm 0.0060$ & $0.0405 \pm 0.0100^{*}$ \\
\hline Mean diastolic pressure & $102.9 \pm 24.64$ & $141.4 \pm 29.89^{*}$ & $103.0 \pm 16.16$ & $128.2 \pm 7.81^{*}$ \\
\hline
\end{tabular}

\section{Electrocardiographic (ECG) analysis:}

The six-week-old L-NAME rats showed no ECG changes compared with WIS. However, the 15-weekold L-NAME rats exhibited increase in QT, QTc and JT intervals when compared to their controls, suggesting impaired ventricular conduction after the intervention (Figure 1, Table 2).

SHR at six weeks of age showed a decrease in heart rate (HR) and an increase in the RR interval when compared with WKY. At this age, SHR also exhibited changes in atrial electrical conduction, such as increased PR interval and P-wave duration. Changes in ventricular function were also observed, with a decrease of QT and QTc intervals, increase in $Q$ wave amplitude and decrease in $\mathrm{R}$ and $\mathrm{S}$ waves' amplitudes. By visual analysis, the ECG revealed a delay in atrial conduction and shortening in ventricular conduction compared with six-week-old WKY (Figure 1, Table 2).

The 15-week-old SHR continued to exhibit lower HR and increased RR and PR interval than WKY, indicating an impairment of atrial conduction with increase in $\mathrm{P}$-wave duration. These rats failed to show a decrease in QT, QTc, JT and P wave amplitude when compared to WKY, probably due to a failure in ventricular conduction at 15 weeks of life, and a decrease in $\mathrm{S}$ wave amplitude at six weeks. Ventricular extrasystole followed by compensatory pauses may characterize impaired ventricular conduction in the SHR when compared with WKY (Figure 1, Table 2).

Regarding the differences between hypertension models used in this study, our results showed that sixweek-old SHR exhibited several changes when compared to L-NAME rats, such as a decrease in HR, increase in $R R$ and $P R$ intervals and duration, increased $P$ wave amplitude, as well as a reduction of QT interval, QTc and JT. At 15 weeks of age, SHR exhibited higher RR interval and $\mathrm{P}$ amplitude than L-NAME, an increase in $\mathrm{P}$ wave amplitude and shorter JT interval when compared to L-NAME (Figure 1, Table 2).

Analysis between the control rats demonstrated that six-week-old WKY had a reduction in PR interval and an increase in QRS interval when compared with WIS. At 15 weeks of age, WKY showed an increase in the QT interval when compared with the WIS (Figure 1, Table 2).

\section{Discussion}

In both hypertension models, the animals showed higher systolic, diastolic and mean pressure values at 15 weeks. Ribeiro et al., ${ }^{22}$ identified progressive increase in blood pressure in L-NAME rats after 4-6 weeks of life, reaching $164 \pm 6 \mathrm{mmHg}$ when compared with $108 \pm 3$ $\mathrm{mmHg}$ in controls. SHR rats developed hypertension at 4-6 weeks of age without any type of intervention and 


\section{WEEKS}
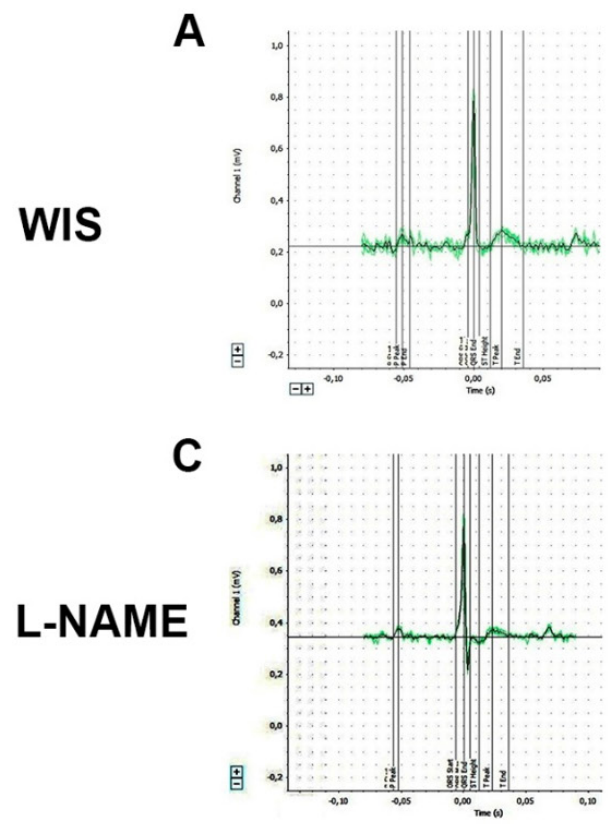

E
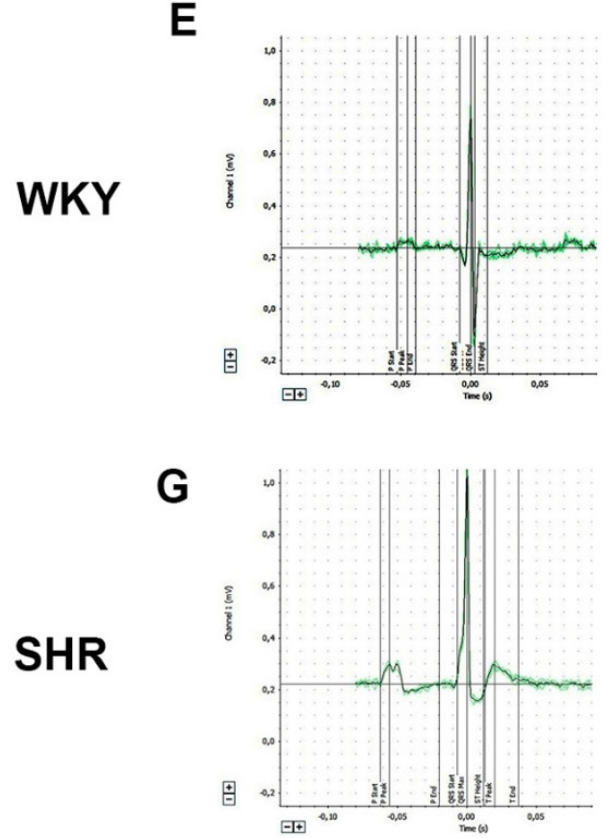

15 WEEKS

B

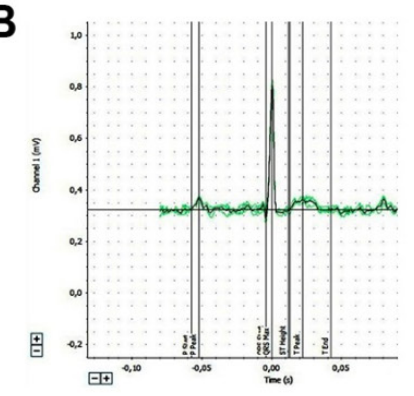

D

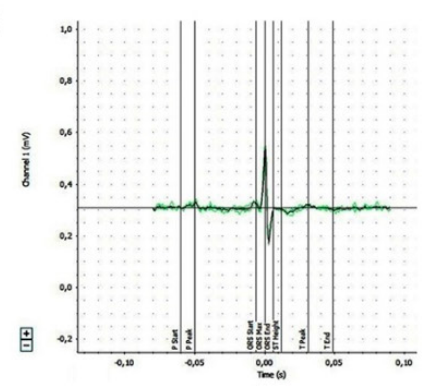

$\mathbf{F}$

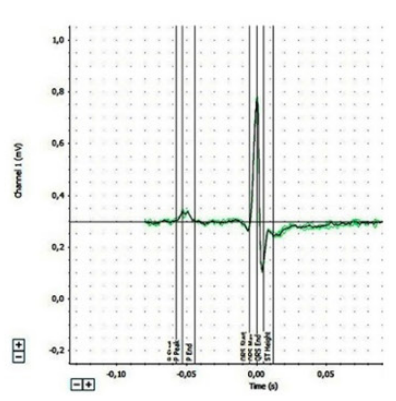

H

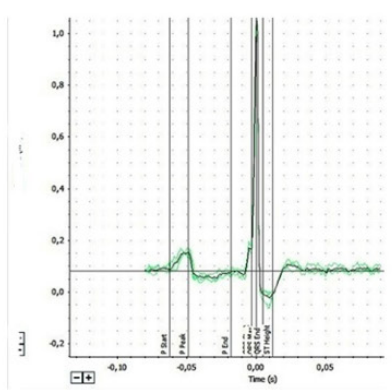

Figure 1 - Electrocardiographic tracing records.

A) WIS at six weeks; B) WIS at 15 weeks; C) L-NAME at six weeks; D) L-NAME at 15 weeks; E) WKY at six weeks; F) WKY at 15 weeks; G) SHR at six weeks; H) SHR at 15 weeks. WIS: Wistar; WKY: Wistar-Kyoto; L-NAME: NG-monomethyl-L-arginine methyl ester (L-NAME)-induced hypertension; SHR: spontaneously hypertensive rats.

exhibited an increased cardiac output with normal total peripheral resistance. ${ }^{9}$ The development of hypertension in SHR progressively promoted structural changes in the heart, which were associated with progressive cardiac hypertrophy. ${ }^{9}$ Our results corroborate those reported by Anishchenko et al., ${ }^{23}$ showing an increase in systolic and 
Table 2 - Electrocardiographic parameters of hypertensive rats and its controls at six and 15 weeks of age

\begin{tabular}{lccccccccc}
\hline & \multicolumn{4}{c}{ Six weeks old } & & \multicolumn{2}{c}{ 15 weeks old } \\
\cline { 2 - 9 } & WIS & L-NAME & WKY & SHR & WIS & L-NAME & WKY & SHR \\
\hline $\begin{array}{l}\text { Heart rate } \\
(\text { BPM })\end{array}$ & $478.4 \pm 16.55$ & $467.4 \pm 34.70$ & $462.8 \pm 38.37$ & $325.8 \pm 74.09^{* *}$ & $427.4 \pm 61.26$ & $420.2 \pm 31.12$ & $426.7 \pm 33.58$ & $351.7 \pm 94.33^{*}$
\end{tabular}

RR interval

(s)

$0.1256 \pm 0.0044 \quad 0.1291 \pm 0.0101 \quad 0.1312 \pm 0.0128 \quad 0.1916 \pm 0.0378^{* *} \quad 0.1433 \pm 0.02390 .1445 \pm 0.0118 \quad 0.1416 \pm 0.0122 \quad 0.1831 \pm 0.0508^{* *}$

PR interval

(s)

$0.0507 \pm 0.0051 \quad 0.0484 \pm 0.0045 \quad 0.0463 \pm 0.0017^{\sharp} \quad 0.0534 \pm 0.0031^{* *} \quad 0.0495 \pm 0.0031 \quad 0.0502 \pm 0.0035 \quad 0.0484 \pm 0.0034 \quad 0.0533 \pm 0.0048^{*}$

P duration

(s)

$0.0162 \pm 0.0045 \quad 0.0137 \pm 0.0041 \quad 0.0153 \pm 0.00390 .0256 \pm 0.0088^{* *} \quad 0.0168 \pm 0.0035 \quad 0.0159 \pm 0.0044 \quad 0.0163 \pm 0.0031 \quad 0.0202 \pm 0.0047^{*}$

QRS interval

(s)

$0.0119 \pm 0.0032 \quad 0.0177 \pm 0.0049 \quad 0.0199 \pm 0.0058^{\sharp} \quad 0.0170 \pm 0.0052 \quad 0.0144 \pm 0.0030 \quad 0.0161 \pm 0.0047 \quad 0.0162 \pm 0.0062 \quad 0.0210 \pm 0.0204$

Qt interval

(s)

$0.0471 \pm 0.0141 \quad 0.0530 \pm 0.0146 \quad 0.0596 \pm 0.0180 \quad 0.0394 \pm 0.0070^{* *} \quad 0.0409 \pm 0.0063 \quad 0.0569 \pm 0.0149^{*} 0.0524 \pm 0.0139^{*} \quad 0.0425 \pm 0.0207$

QTc (s)

$0.1333 \pm 0.0405 \quad 0.1484 \pm 0.0438 \quad 0.1664 \pm 0.0547 \quad 0.0909 \pm 0.0154^{* *} \quad 0.1094 \pm 0.0205 \quad 0.1495 \pm 0.0383^{*} 0.1398 \pm 0.0373 \quad 0.1042 \pm 0.0603$

T peak $\mathrm{T}$

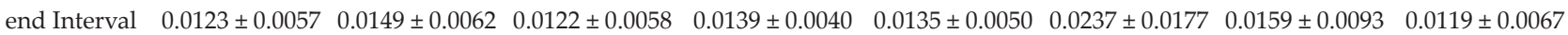
(s)

JT interval

(s)

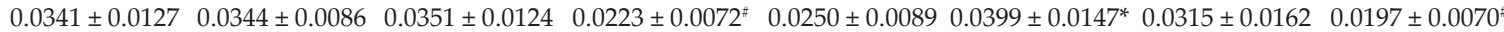

P amplitude $(\mathrm{mV})$

$0.0376 \pm 0.0046 \quad 0.0315 \pm 0.0238 \quad 0.0448 \pm 0.0220 \quad 0.0460 \pm 0.0139^{*} \quad 0.0261 \pm 0.0153 \quad 0.0173 \pm 0.02290 .0309 \pm 0.0188 \quad 0.0487 \pm 0.0178^{* *}$ Q amplitude $(\mathrm{mV})$

R amplitude $(\mathrm{mV})$

$0.0053 \pm 0.0158-0.0029 \pm 0.0231-0.0240 \pm 0.0251 \quad 0.0023 \pm 0.0105^{*}-0.0092 \pm 0.0218-0.0074 \pm 0.0476-0.0079 \pm 0.0101-0.0089 \pm 0.0720$ 0.5

S amplitude $(\mathrm{mV})$

T amplitude $(\mathrm{mV})$

\begin{tabular}{lcccccccc} 
ST Height & $-0.0131 \pm 0.0317$ & $0.0094 \pm 0.0329$ & $-0.0267 \pm 0.0074$ & $-0.0412 \pm 0.0343$ & $-0.0156 \pm 0.0380$ & $-0.0202 \pm 0.0224$ & $-0.0387 \pm 0.0237$ & $-0.0468 \pm 0.1094$ \\
First beat & $1,251 \pm 87.17$ & $1,208 \pm 72.64$ & $1,172 \pm 98.40$ & $830.6 \pm 178.1$ & $1,097 \pm 161.3$ & $1,055 \pm 97.52$ & $1,082 \pm 86.60$ & $893.7 \pm 246.8$ \\
Last beat & $1,254 \pm 87.17$ & $1,211 \pm 72.64$ & $1,175 \pm 98.40$ & $833.6 \pm 178.1$ & $1,100 \pm 161.3$ & $1,058 \pm 97.52$ & $1,085 \pm 86.60$ & $896.7 \pm 246.8$ \\
\hline
\end{tabular}

Electrocardiographic parameters of Wistar (WIS), Wistar-Kyoto (WKY), NG-monomethyl-L-arginine methyl ester (L-NAME)-induced hypertension, and spontaneously hypertensive rats (SHR) rats at six and 15 weeks of age. Data are presented as mean \pm SD. ${ }^{*} p<0.05$ compared to control (WIS vs. L-NAME; WKY vs. SHR); \#p $<0.05$ WIS vs. WKY; and L-NAME vs. SHR, $n=6$.

diastolic blood pressure in SHR compared with WKY at six weeks of life. ${ }^{23}$ There are no data comparing ECG measures between WIS and WKY rats in the literature.

SHR showed a decrease in HR when compared to WKY and L-NAME. A possible interpretation of this data is the involvement of cyclic adenosine monophosphate
(cAMP), which may be less available due to increased depletion induced by phosphodiesterase 3A (PDE3A). PDE3A is considered the main CAMP regulator in cardiomyocytes and an important regulator of cardiac contractility. ${ }^{24-26}$ Increased expression of PDE3A results in reduced availability of cAMP and 
changes in the cyclic nucleotide balance, with a direct relationship with many diseases, including hypertension. ${ }^{27}$ The availability of cAMP is also linked to hyperpolarization-activated, cyclic nucleotide-gated (HCN) channels, where beta-adrenergic stimulation activates adenylate cyclase, resulting in an increase in cAMP synthesis. ${ }^{28}$ Increased cAMP raises the membrane potential, leading to higher depolarization rate, and subsequent increase in heart rate, acting as a second messenger in the modulation of $\mathrm{HCN}$ channels. ${ }^{29}$ This could be a possible explanation for the cardiac abnormalities found in WKY. However, studies in the literature that explain these effects are scarce and technical limitations avoid us to validate this hypothesis, so further studies are needed to confirm it.

El-Mosallamy et al., ${ }^{30}$ demonstrated that L-NAME rats exhibited increase in RR interval, longer duration of the $\mathrm{P}$ wave and ST-segment elevation. However, in our results, the treatment with L-NAME induced an increase in QT, QTc and JT intervals at 15 weeks. Prolongation of QT and JT intervals are considered an indication of ventricular arrhythmia, the major cause of sudden death in hypertension. ${ }^{12,31}$ The RR interval may change with dysregulation of the atrial electrical activity, and ceases to be constant in irregular heartbeats. ${ }^{32}$ SHR showed increased RR interval, resulting in bradycardia. This change may be related to the ventricular extrasystole observed in this strain..$^{33}$

The PR interval corresponds to the period that electrical signals are delayed at the atrioventricular (AV) node, before it travels through the ventricular branches to induce cardiac depolarization and may be prolonged during AV nodal dysfunction. ${ }^{34}$ Therefore, increased PR interval is also linked to bradycardia. ${ }^{32} \mathrm{We}$ found a failure in atrial conduction in SHR rats, which are consistent with the studies by Hazari et al., 35,36 that showed prolongation of PR interval in SHR compared with WKY

In addition to the atrial conduction delay, SHR also showed impaired ventricular conduction, with a decrease in QT and QTc, and shortening of QT at six weeks of life. These results are commonly related to electrolyte disorders such as hyperkalemia. ${ }^{37}$ Hazari et al., ${ }^{35}$ described that 12 -week-old SHR have prolongation of the interval QT, JT and QTc. In our study, six-week-old SHR exhibited shorter duration of QT, JT and QTc intervals, which was probably related to hyperkalemia. ${ }^{38-40}$ The ECG confirmed that SHR, beyond the electrical conduction failure, show T-wave inversion, which may lead to ischemic heart failure with advanced hypertension. Animal restraining, restraintstress and difficulties with placing the electrodes in the same position in different rats are significant limitations of the method.

\section{Conclusion}

The present study shows that cardiac function is different in SHR compared with L-NAME rats. While SHR showed cardiac dysfunction, L-NAME exhibited changes in ventricular performance. Although decreased levels of PDE3A may have contributed to the changes observed in WKY, it was not sufficient to cause hypertension in this strain. Thus, all the hypertension models used in this study featured an increase in blood pressure, but each with its distinct adaptive mechanism. These results can serve as a basis for future studies on different types and models of hypertension.

\section{Potential Conflict of Interest}

No potential conflict of interest relevant to this article was reported.

\section{Sources of Funding}

This study was funded by CAPES, Faepex-PRP, SAE-Unicamp and FAPESP.

\section{Study Association}

This article is part of the thesis master submitted by Ana Gabriela Conceição-Vertamatti, from Universidade de Campinas.

\section{Ethics approval and consent to participate}

This study was approved by the Committee for Ethics in Animal Experimentation (CEUA) under the protocol number 2615-1. All the procedures in this study were in accordance with the 1975 Helsinki Declaration, updated in 2013. Informed consent was obtained from all participants included in the study.

\section{Author contributions}

Conception and design of the research: Grassi-Kassisse DM. Acquisition of data: Conceição-Vertamatti AG, Borghi F, Ishizu LY, Costa GT, Ramos LA, Areas MA. Analysis and interpretation of the data: Conceição- 
Vertamatti AG, Borghi F, Ramos LA, Areas MA, GrassiKassisse DM. Statistical analysis: Conceição-Vertamatti AG, Borghi F, Grassi-Kassisse DM. Obtaining financing: Grassi-Kassisse DM. Writing of the manuscript:
Conceição-Vertamatti AG, Borghi F, Ishizu LY, Costa GT, Grassi-Kassisse DM. Critical revision of the manuscript for intellectual content: Conceição-Vertamatti AG, Borghi F, Areas MA, Grassi-Kassisse DM.

\section{References}

1. McEwen BS. Protection and damage from acute and chronic stress: allostasis and allostatic overload and relevance to the pathophysiology of psychiatric disorders. Ann N Y Acad Sci. 2004 Dec;1032:1-7.

2. Peters A, McEwen BS. Stress habituation, body shape and cardiovascular mortality. Neurosci Biobehav Rev. 2015 Sep;56:139-150.

3. Hamer M, Endrighi R, Venuraju SM, Lahiri A, Steptoe A. Cortisol responses to mental stress and the progression of coronary artery calcification in healthy men and women. PLoS One 2012;7(2):e31356.

4. World Health Organization. A global brief on hypertension: silent killer, global public health crisis. Geneva: WHO; 2013.

5. Feihl F, Liaudet L, Levy BI, Waeber B. Hypertension and microvascular remodelling. Cardiovasc Res. 2008;78(2):274-85.

6. Pereira MC, Ribeiro L. Stress, catecholamines and cardiovascular risk. Arq Med. 2012;26(6):245-53.

7. Vaněčková I, Maletínská L, Behuliak M, Nagelová V, Zicha J, Kuneš J. Obesity-related hypertension: possible pathophysiological mechanisms. J Endocrinol. 2014;223(3):R63-R78.

8. Badyal D, Lata H, Dadhich AP. Animal models of hypertension and effect of drugs. Indian J Pharmacol. 2003;35:349-62.

9. Dornas WC, Silva ME. Animal models for the study of arterial hypertension. J Biosci. 2011;36(4):731-7.

10. Conceicao-Vertamatti AG, Borghi F, Canova F, Grassi-Kassisse DM. History of vascular reactivity models and their involvement in hypertension pathogenesis. Vasa. 2017;46(6):431-9.

11. Cuspidi C, Rescaldani M, Sala C, Negri F, Grassi G, Mancia G. Prevalence of electrocardiographic left ventricular hypertrophy in human hypertension: an updated review. J Hypertens. 2012;30(11):2066-73.

12. Mozos I, Caraba A. Electrocardiographic predictors of cardiovascular mortality. Dis Markers. 2015;2015:727401.

13. Mansur PH, Cury LK, Destro-Filho JB, Resende ES, Destro JP, de Oliveira LM, et al. Analysis of electrocardiographic recordings associated with acute myocardial infarction. Arq Bras Cardiol. 2006;87(2):106-14.

14. Rogers K. The Cardiovascular System. Britannica Educational Pub, 2011.

15. Magnani JW, Gorodeski EZ, Johnson VM, Sullivan LM, Hamburg NM, Benjamin EJ, et al. P wave duration is associated with cardiovascular and all-cause mortality outcomes: the National Health and Nutrition Examination Survey. Heart Rhythm. 2011;8(1):93-100.

16. Liew R. Electrocardiogram based predictors of sudden cardiac death in patients with coronary artery disease. Clin Cardiol. 2011;34(8):466-73.

17. Strauss DG, Selvester RH, Lima JA, Arheden H, Miller JM, Gerstenblith G, et al. ECG quantification of myocardial scar in cardiomyopathy patients with or without conduction defects correlation with cardiac magnetic resonance and arrhythmogenesis. Circ Arrhythm Electrophysiol. 2008;1(5):327-36.

18. Haarmark C, Graff C, Andersen MP, Hardahl T, Struijk JJ, Toft E, et al. Reference values of electrocardiogram repolarization variables in a healthy population. J Electrocardiol. 2010;43(1):31-9.

19. Paulis L, Unger T. Novel therapeutic targets for hypertension. Nat Rev Cardiol. 2010;7(8):431-41.
20. Conceicao-Vertamatti AG, Ramos LA, Calandreli I, Chiba AN, Franco DW, Tfouni E, et al. Vascular response of ruthenium tetraamines in aortic ring from normotensive rats. Arq Bras Cardiol. 2015;104(3):185-94.

21. Feketa VV, Balasubramanian A, Flores CM, Player MR, Marrelli SP. Shivering and tachycardic responses to external cooling in mice are substantially suppressed by TRPV1 activation but not by TRPM8 inhibition. Am J Physiol Regul Integr Comp Physiol. 2013;305(9):R1040-50.

22. Ribeiro MO, Antunes E, de Nucci G, Lovisolo SM, Zatz R. Chronic inhibition of nitric oxide synthesis. A new model of arterial hypertension. Hypertension. 1992;20(3):298-303.

23. Anishchenko AM, Aliev OI, Sidekhmenova AV, Shamanaev AY, Plotnikov MB. Dynamics of blood pressure elevation and endothelial dysfunction in SHR rats during the development of arterial hypertension. Bull Exp Biol Med. 2015:159(5):591-3.

24. Oikawa M, Wu M, Lim S, Knight WE, Miller CL, Cai Y, et al. Cyclic nucleotide phosphodiesterase $3 \mathrm{~A} 1$ protects the heart against ischemiareperfusion injury. J Mol Cell Cardiol. 2013 Nov;64:11-9.

25. Lakics V, Karran EH, Boess FG. Quantitative comparison of phosphodiesterase mRNA distribution in human brain and peripheral tissues. Neuropharmacology. 2010;59(6):367-74.

26. Beca S, Ahmad F, Shen W, Liu J, Makary S, Polidovitch N, et al. PDE3A regulates basal myocardial contractility through interacting with SERCA2a-signaling complexes in mouse heart. Circ Res. 2013;112(2):289-97.

27. Yan C. Cyclic nucleotide phosphodiesterase 1 and vascular aging. Clin Sci. 2015;129(12):1077-81.

28. DiFrancesco D. Cardiac pacemaker (If) current: physiological and pharmacological properties. Hosp Chron. 2006;Suppl 1:151-5.

29. DiFrancesco D, Tortora P. Direct activation of cardiac pacemaker channels by intracellular cyclic AMP. Nature. 1991;351(6322):145-7.

30. El-Mosallamy AE, Sleem AA, Abdel-Salam OM, Shaffie N, Kenawy SA. Antihypertensive and cardioprotective effects of pumpkin seed oil. J Med Food. 2012;15(2):180-9.

31. Fish JM, Di Diego JM, Nesterenko V, Antzelevitch C. Epicardial activation of left ventricular wall prolongs QT interval and transmural dispersion of repolarization: implications for biventricular pacing. Circulation. 2004;109(17):2136-42

32. Feldman J, Goldwasser GP. Electrocardiogram: recommendations for interpretation. Rev. SOCERJ. 2004;17(4):251-6.

33. Nicolau JC, Polanczyk CA, Pinho JA, Bacellar MSC, Ribeiro DGL, Darwich RN, et al. Diretriz de interpretação de eletrocardiograma de repouso. Arq Bras Cardiol. 2003;80(supl II):1-18.

34. Verweij N, Leach IM, van den Boogaard M, van Veldhuisen DJ, Christoffels VM, Hillege HL, et al. Genetic determinants of P wave duration and PR segment. Circ Cardiovasc Genet. 2014;7(4):475-81.

35. Hazari MS, Haykal-Coates N, Winsett DW, Costa DL, Farraj AK Continuous electrocardiogram reveals differences in the short-term cardiotoxic response of Wistar-Kyoto and spontaneously hypertensive rats to doxorubicin. Toxicol Sci. 2009:110(1):224-34.

36. Hazari MS, Haykal-Coates N, Winsett DW, Costa DL, Farraj AK. A single exposure to particulate or gaseous air pollution increases the risk of 
aconitine-induced cardiac arrhythmia in hypertensive rats. Toxicol Sci. 2009:112(2):532-42.

37. Khera S, Jacobson JT. Short QT syndrome in current clinical practice. Cardiol Rev. 2016;24(4):190-3.

38. Bjerregaard P, Nallapaneni H, Gussak I. Short QT interval in clinical practice. J Electrocardiol. 2010;43(5):390-5.
39. Friedmann AA, Grindler J, Oliveira CAR, Fonseca AJ. Encurtamento do intervalo QT. Diagn Tratamento. 2012;17(4):192-4.

40. Bélichard P, Pruneau D, Rouet R, Salzmann J, et al. Electrophysiological responses of hypertrophied rat myocardium to combined hypoxia, hyperkalemia, and acidosis. J Cardiovasc Pharmacol. 1991;17:S141-5. 